\title{
Sensitive and Rapid Detection of Traditional Chinese Herbs by Loop-Mediated Isothermal Amplification Method and Real-Time Fluorescence Quantitative PCR
}

\author{
Min Min Ma ${ }^{1}$, Dan Jiang ${ }^{2}$, Shuang Ya Li ${ }^{1}$, Yuan Wu', Ju Meng1, Jiang Yao Huang' \\ ${ }^{I}$ Minzu University of China - College of life and enviroment science;Beijing Engineering Research Center of Food \\ Environment and Public Health, Beijing, China; ${ }^{2}$ Liaoning Inspection and Quarantine Bureau - Dalian, Liaoning, \\ China.
}

\begin{abstract}
Adulterant herbal materials are threats to import and export trade and consumer safety. In this study, we established a simple and rapid examination system for the detection of Phellodendron chinense Schneid. Two detection methods, real-time fluorescence quantitative PCR (real-time PCR) and loop-mediated isothermal amplification (LAMP), were developed for traditional Chinese medicine detection, and their specificity and sensitivity were compared. The DNA of P. chinense was extracted and its special periods amplified with designed primers. Real-time PCR and LAMP experiments were conducted to test the specificity of primers in contrast to other similar species. The template concentration was diluted from $10^{1} \mathrm{ng} / \mu \mathrm{L}$ to $10^{-5} \mathrm{ng} / \mu \mathrm{L}$ in order to contrast sensitivity between real-time PCR and LAMP. Real-time PCR and Lamp method has shown specificity because P. chinense was positive as opposed to other negative similar species. The Lamp method could detect a limited DNA concentration of $10^{-4} \mathrm{ng} / \mu \mathrm{L}$ in 60 minutes with same sensitivity to real-time PCR. The results indicate that real-time PCR and LAMP are sensitive, accurate and specific in detection of P. chinense. However, LAMP is more convenient and cast less time. What's more, expensive equipments are not necessary for LAMP detector. For a better detection, we suggest an establishment of a real-time PCR and LAMP method for TCM market supervision which depends on DNA barcode sequences and LAMP.
\end{abstract}

Keywords: Traditional Chinese medicine; Real-time PCR; Phellodendron chinense Schneid; LAMP; Specificity; Sensitivity

\footnotetext{
*Author for correspondence: mm9217@163.com
} 


\section{INTRODUCTION}

Counterfeit drugs are always sold in markets leading to adverse effects such as drug resistance, and eventually death ${ }^{[1-3]}$. In developing countries, the percentage of counterfeit drug sales is approximately $10 \%$. That proportion would be greater than $50 \%$, considering if medicines are purchased online ${ }^{[4,5]}$. Drug counterfeiting posed a serious threat to personal safety resulting to serious damage in the interests of consumers. Counterfeit drug use has been dramatically increasing in recent years. For example, the proportion of counterfeit medicines has reached $80 \%$ in African countries ${ }^{[6]}$ threatening the normal import and export trade. Therefore, the absence of suitable and rapid identification methods corresponds to a rise in number of reported cases concerning counterfeit medicine ${ }^{[6]}$.

Traditional Chinese Medicine (TCM) plays a pivotal role in disease prevention, treatment and research as demonstrated in the clinical efficacy of TCM against certain diseases which are ineffective or has associated side effects ${ }^{[7]}$. $P$. chinense is a famous and precious traditional Chinese medicine. According to TCM practice, $P$. chinense is effective in removing heat and toxic substances. Most of traditional Chinese medicines are been distributed in desert regions, which leads to their shortage. In recent years, there has been a huge increase in the use of herbal products. However, some defective goods and falsify herbs are been filled with Chinese herbal medicine market because of the influence of Profit-driven as well as resource depletion which poses a major public health risk. Medical plants are the basis of genuine drug production, but recently, it's reported that some counterfeit or adulterant drugs caused life-threatening poisonings. For example, it's reported that approximately $50 \%$ of artesunate tablet samples extracted from Artemisia annua L. in Southeast Asia are adulterant drugs ${ }^{[8]}$. Most importantly, it is often reported that severe kidney damage caused by adulteration with Aristolochia species because of aristolochic acid toxicity ${ }^{[9-11]}$. All of these life-threatening poisoning cases threaten the safe use of TCM. Therefore, solving the medicinal authenticity identification becomes an important project to improve the quality of medicinal materials and guarantee for the import and export.

Traditional identification method used in Chinese herbal medicine include character identification, microscopic identification and physical and chemical identification. Although these methods are simple and direct, their subjectivity is strong. Their accuracy depend on human experience and existence of many disadvantages such as 'the effects was not beautiful, accuracy was not enough and so on'. The classic shape classification and traditional identification method is unable to meet the needs of identification of traditional Chinese medicine, especially for medicines that are sliced to pieces after complicated process ${ }^{[12]}$. Besides, none of these methods alone can definitively identify closely related species that share remarkably similar morphological characteristics and chemical profiles ${ }^{[13]}$. As a result, it's urgent to establish rapid and simple identification procedures for the rapid inspection of raw herbal materials.

With the development of molecular biology and equipment technology, Chinese herbal medicine field have launched some new identification methods that show vigorous vitality. Real-time PCR technology is a popular molecular detection technology in recent years with many advantages on detection such as high efficiency, strong sensitivity, perfectly specificity and so on. Real-time monitoring can be achieved through an observation curve in the reaction process ${ }^{[14,15]}$. Since LAMP was first reported by Notomi et al. in 2000, it has attracted a lot of attention as a potentially rapid, accurate, sensitive, and cost-effective novel nucleic acid amplification method ${ }^{[16]}$. A special advantage of LAMP is the ability to amplify 
specific sequences of DNA under stationary temperature between 63 and $65^{\circ} \mathrm{C}{ }^{[17]}$. Besides, a positive reaction with LAMP can be easily judged by the naked eye, without electrophoresis ${ }^{[18]}$. The LAMP method has now been developed as commercial kits and some of them have been recommended as methods for routine identification and surveillance of pathogens in some countries ${ }^{[19]}$.

Most of the Real-time PCR and LAMP assays are developed for the detection of microorganism ${ }^{[20-24]}$, but few on the detection of Chinese herbs. In this study, we sought to establish a LAMP and Real-time protocol and examine its reliability in detection of traditional Chinese medicine targeting ITS2 or psba-trnh gene, named as DNA bar coding gene ${ }^{[12]}$. The advantages and limitations of Real-time PCR and LAMP are also discussed and the sensitivity of LAMP and Real-time PCR was compared.

\section{MATERIAL AND METHODS}

\section{Traditional Chinese medicine}

In this experiment, five (5) Chinese herbs with similarity to the original herbs were taken and contrasted to the separate negative samples consisting of three herbs, to test specificity (Table 1). In fact, there are three rules taken to choose these negative samples. First, these herbs are similar to $P$. chinense in regards to color and shape. When these herbs are processed into dusty or small pieces, it's difficult to distinguish them from $P$. chinense based on shape, color and smell. Secondly, these herbs have similarity in therapeutic effect on disease as described by Chinese pharmacopoeia. However, these herbs are cheaper than $P$. chinense but are less effective. Last, in the practical detection of Entry-Exit Inspection and Quarantine Bureau, these herbs are always be found adulterated in the detection of $P$. chinense.

Table 1. P. chinense used in this study for positive and negative samples.

\begin{tabular}{lll}
\hline Experimental samples & Negative samples & NO. tested \\
\hline & Gardenia jasminoides Ellis. & CH1 \\
& Gentiana scabra Bunge. & $\mathrm{CH} 2$ \\
P. chinense & Anemarrhena asphodeloides Bunge. & $\mathrm{CH} 3$ \\
& Scutellaria baicalensis Georgi. & $\mathrm{CH} 4$ \\
& Coptis chinensis Franch. & $\mathrm{CH} 5$ \\
\hline
\end{tabular}

DNA extraction and preparation from Chinese herbs

DNA was extracted by improved CTAB method as described by Zhonggang Duan. ${ }^{[25]]}$ The DNA was dissolved in $60 \mu \mathrm{L}$ TE or $\mathrm{ddH}_{2} \mathrm{O}$ and stored in $-20^{\circ} \mathrm{C}$ before use. Sensitivity test involve DNA template dilution with sterile water ranging from $10^{1}$ to $10^{-5} \mathrm{ng} / \mu \mathrm{l}$. Blank control was performed using sterile water instead of the DNA template.

\section{Sequence screen and special primers design}

The detection of traditional Chinese medicine depends on DNA bar coding genes described by Chen $\mathrm{SL}^{[13]}$. The bar coding gene was filtered and special gene of $P$. chinense was separately chosen according to the amplification sequence (Table 2). At first, we took ITS2 and Genebank NO. as keywords to search on NCBI. A Blast N program was processed in $\mathrm{Nr}$ database to find similarly sequence and download all sequences in FASTA format. Then, similarly analysis of these sequence was processed with the software named MEGA 6.0 to find the special region. At last, the primers were designed in these special regions by a software named Primer Express3.0. 


\section{Real-time PCR reaction}

Firstly, primers specificity was processed by PCR. The PCR products were observed under $110 \mathrm{v}$ and $1 \%$ agarose gel electrophoresis, then gel imaging system photographed. Real-time PCR was carried out using a Q-pcr Mix kit (GeneCopoeia, USA). In brief, Real-PCR was carried out with a $20 \mu \mathrm{L}$ mixture containing $2 \mu \mathrm{L}$ primer F and primer R, $10 \mu \mathrm{L}$ of Q-PCR mix, $0.4 \mu \mathrm{L}$ of Rox Reference Dye, $3.6 \mu \mathrm{l}$ of $\mathrm{ddH}_{2} \mathrm{O}$, and $2 \mu \mathrm{L}$ of the DNA template. The process had three steps including 95 ${ }^{\circ} \mathrm{C} 30 \mathrm{~s}$, one cycle ; $95^{\circ} \mathrm{C} 5 \mathrm{~s}, 58.5^{\circ} \mathrm{C} 30 \mathrm{~s}, 40$ cycle and get fluorescent when $72^{\circ} \mathrm{C}$.

\section{LAMP reaction}

The LAMP reaction depends on DNA bar coding genes. Thus, the bar coding gene was filtered to obtain $P$. chinense special gene in Real-time PCR. The special gene and LAMP reaction are GeneBank NO. GQ434820 and KP089168, respectively. The LAMP reaction was conducted as described by Notomi et al. ${ }^{[16]}$ and Savan et al. ${ }^{[26]}$. Primers for LAMP were designed using primer software PrimerExplorer and online website (http://primerexplorer.jp/e/), targeting the conserved region of ITS2 gene ${ }^{[13]}$. LAMP reactions were carried out using a Loopamp kit as described by Eiken Chemical Co. Ltd., Tokyo, Japan. In brief, LAMP reaction mixture containing 40 pmol of FIP and BIP in total of $25 \mu \mathrm{L}, 5$ pmol of $\mathrm{F} 3$ and B3, $12.5 \mu \mathrm{L}$ of $2 \times$ reaction mixture $\left(40 \mathrm{mM}\right.$ Tris- $\mathrm{HCl}[\mathrm{pH} 8.8], 20 \mathrm{mM} \mathrm{KCl}, 16 \mathrm{mM} \mathrm{MgSO}_{4}, 20 \mathrm{mM}$ $\left[\mathrm{NH}_{4}\right]_{2} \mathrm{SO}_{4}, 0.2 \%$ Tween $20,1.6 \mathrm{M}$ betaine, $2.8 \mathrm{mM}$ of each deoxy nucleotide triphosphate [dNTP]), $1 \mu \mathrm{L}$ Bst DNA polymerase, and $2 \mu \mathrm{L}$ of the DNA template. $1 \mu \mathrm{L}$ fluorescent detection reagent (Eiken Chemical Co. Ltd., Japan) was added to some of the reactions, and the volume was adjusted accordingly. The reaction mixture was incubated at $65^{\circ} \mathrm{C}$ for $90 \mathrm{~min}$, then at $80^{\circ} \mathrm{C}$ for $2 \mathrm{~min}$ to the end of reaction in a Loopamp real-time turbidimeter (LA-320C and LA-500, Teramecs Co. Ltd., Japan).

\section{RESULTS AND DISSCUSSION}

\section{Specificity of the Real-time $\mathrm{PCR}$ reaction}

A previous study ${ }^{[13]}$ has compared the PCR amplification efficiency of some gene sequence such as psbA-trnH, ITS2 and ITS sequence across 400 Chinese herb samples. The success rates for $p s b A$-trnH and ITS2 sequence was $92.8 \%$. In this study, ITS2 was chosen as bar coding sequence after filtering off the other sequences. The ITS2 primers pair with highest success rates as listed in Table 2.

Table 2. Nucleotide sequences of real-time PCR primers designed in this study.

\begin{tabular}{lllll}
\hline Species & $\begin{array}{l}\text { Name of } \\
\text { primers }\end{array}$ & Sequence of primers $\left(5^{\prime}-3^{\prime}\right)$ & $\begin{array}{l}\text { Annealing } \\
\text { temperature }\end{array}$ & $\begin{array}{l}\text { Size } \\
\text { sequence }\end{array}$ \\
\hline \multirow{2}{*}{. chinense } & ITS2F1 & GTTGGCCCAAATTCGAGTCC & $58^{\circ} \mathrm{C}$ & $112 \mathrm{bp}$ \\
& ITS2R1 & GGTCCCTGAGTCCCGAAAAG & & \\
\hline
\end{tabular}

In conventional PCR, DNA template of $P$. chinense have respective products, while DNA template from others species similar to $P$. chinense cannot be amplified (Fig 1A). The real-time PCR has shown that $\mathrm{Ct}$ value of $P$. chinense is $19.86,19.65$ and 19.77, while the $\mathrm{Ct}$ value of $\mathrm{CH} 1$ to $\mathrm{CH} 5$ is greater than 30 (Fig 1B). The pair of primers specified to $P$. chinense and real-time PCR can detect Chinese herbs with higher speed and higher specify. Compared with conventional PCR, real-time PCR cast less time and could monitor the reaction in real-time by observing the curve in 
reaction process. However, real-time PCR is more expensive considering relative equipment and kits.

A
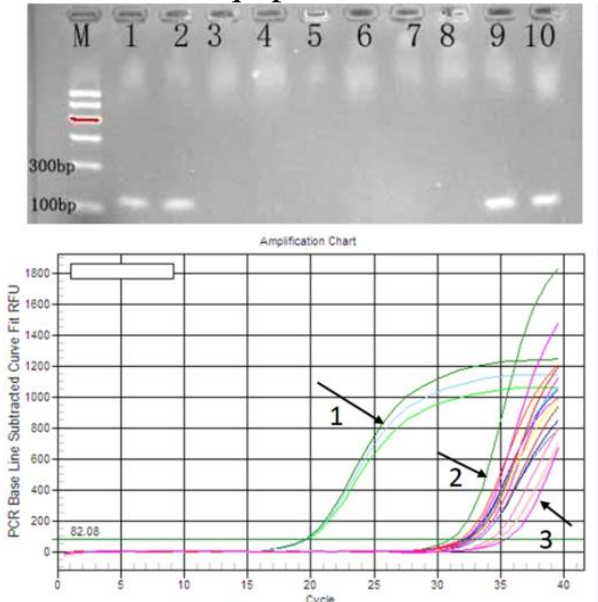

Figure 1. Specify amplification of $P$. chinense by PCR (A) and Real-time PCR (B). (A) Template DNA were from lanes 1,2,9,10, $P$. chinense; 3, $\mathrm{CH} 1 ; 4, \mathrm{CH} 2 ; 5, \mathrm{CH} 3 ; 6, \mathrm{CH} 4 ; 7, \mathrm{CH} 5 ; 8$, blank control. (B) Template DNA were from1, P. chinense; 2 , Chinese herbs NO.CH1-CH5; 3 blank control.

\section{Specificity of the LAMP reaction}

LAMP requires a set of four primers (B3, F3, BIP and FIP), recognizing six distinct sequences within a target DNA in total (Fig 2). At first, three groups of primers were designed and filtered to select the best group depending on initial time of turbidity. Turbidity occur after 70 minutes on one of groups, while the other group didn't show any line until the reaction was completed (Fig 3A). An optimal group of primers for LAMP reactions and design loop-primers was chosen. The LAMP reaction was positive and have shown lines after 20 minters for the $P$. chinense and none to the other tested similar species (Fig 3B). That is suggestive that, LAMP reaction is specific to $P$. chinense. The early appearance in turbidity with the addition of loopprimers, indicates that addition of loop-primer can accelerate LAMP reaction.

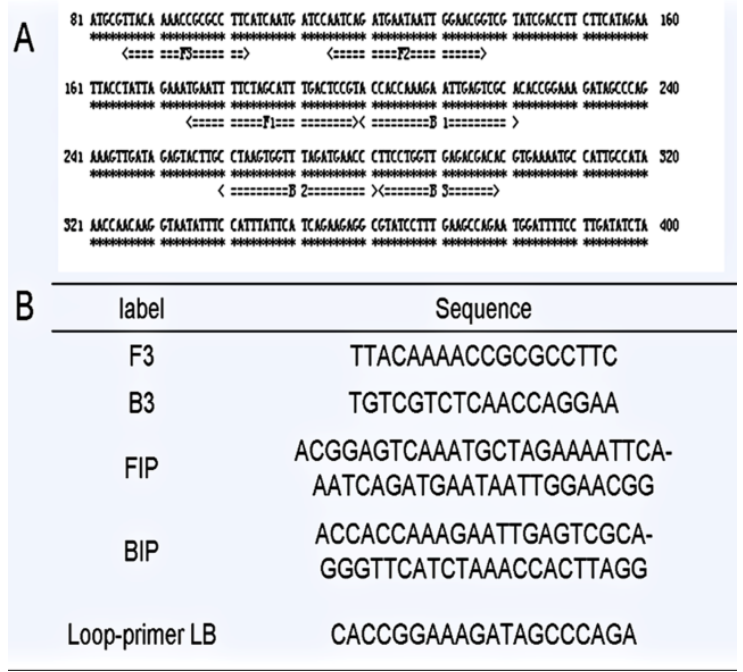

Figure 2. The nucleotide sequence and primers of LAMP methods targeted. (A) Nucleotide sequence of $P$. chinense used to design LAMP primers. Underlines indicate the positions of the targeting sequences. (B) Nucleotide sequences of the best primer group of $P$. chinense. B2c, F1c and B3c represent complementary sequences to $\mathrm{B} 2, \mathrm{~F} 1$ and $\mathrm{B} 3$, respectively. 


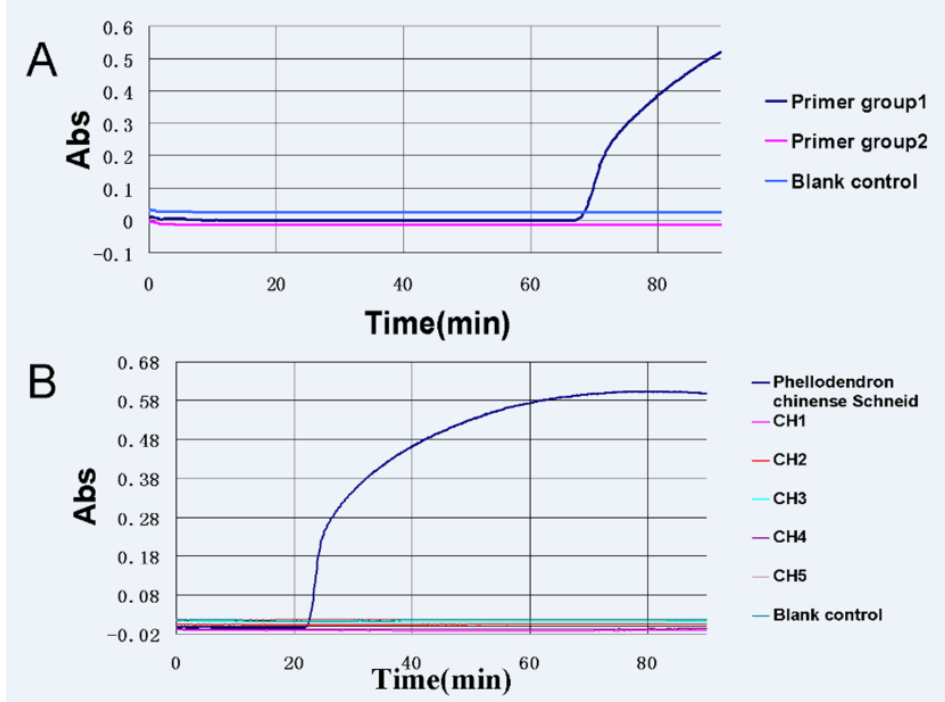

Figure 3. Specify detection of LAMP method for the $P$. chinense. (A) Screening the best group of $P$. chinense LAMP primers by the real-time amplification of turbidity. (B) Controlled test between $P$. chinense and other similar species (CH1-CH5) with the best group of primers and addition of loop-primers in LAMP detection.

\section{Comparison of Sensitivity between LAMP reaction and the Real-time PCR reaction}

The detection limit concentration of real-time PCR assay was $10^{-4} \mathrm{ng} / \mu \mathrm{L}$ of herbs DNA (Fig 4.). It has been shown that $\mathrm{Ct}$ value was increasing with dilution of DNA template. The $\mathrm{Ct}$ value was over 30 when DNA concentration is $10^{-5} \mathrm{ng} / \mu \mathrm{L}$. It have been demonstrated that real-time PCR could detect less concentration of DNA template compared to conventional PCR, which means detection sensitivity was higher.

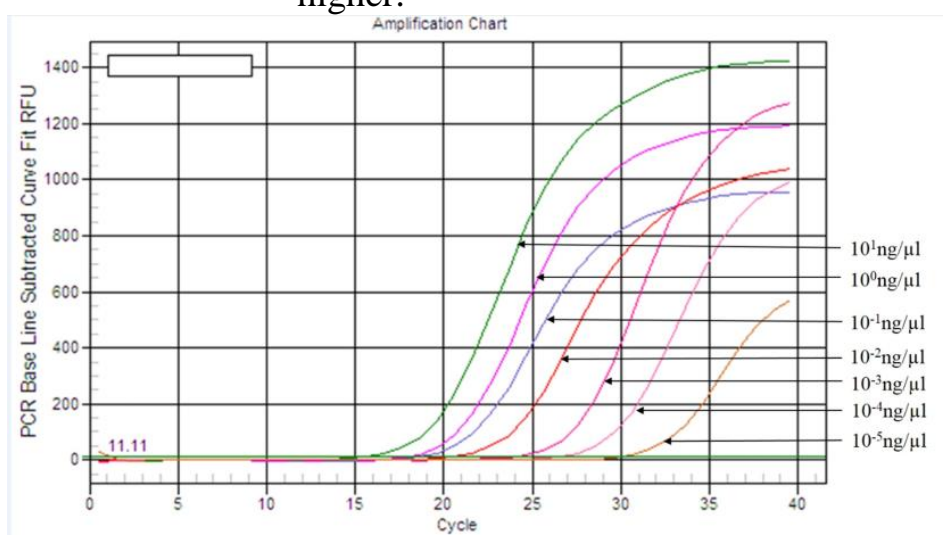

Figure 4. Sensitivity detection of real-time PCR method for the $P$. chinense. Real-time PCR reaction with different concentration DNA of $P$. chinense. Lanes 1-7: $10^{1} \mathrm{ng} / \mu \mathrm{L}, 10^{0} \mathrm{ng} / \mu \mathrm{L}, 10^{-1} \mathrm{ng} / \mu \mathrm{L}, 10^{-2} \mathrm{ng} / \mu \mathrm{L}, 10^{-3} \mathrm{ng} / \mu \mathrm{L}$, $10^{-4} \mathrm{ng} / \mu \mathrm{L}, 10^{-5} \mathrm{ng} / \mu \mathrm{L}$

The sensitivity of LAMP was compared with real-time PCR, using the same template DNA. With the reduction of DNA template, turbidity is lower. However, no turbidity is detected when the concentration is $10^{-5} \mathrm{ng} / \mu \mathrm{L}$ (Fig 5A). That is consistent when the amplification time begin to vary from 20 to 35 minutes with the dilution of DNA. Also, no amplification was detected when the concentration is lower than $10^{-4} \mathrm{ng} / \mu \mathrm{L}$ (Fig $5 \mathrm{~B}$ ). Visual inspection of the LAMP products is conducted by adding fluorescent detection reagent. The appearance of green color shows occurrence of reaction, while a brown color indicates a negative reaction(Fig 
5C). The LAMP reaction occurred in a sample containing $10^{-4} \mathrm{ng} / \mu \mathrm{L}$ template, which validates a sensitivity detection in $10^{-4} \mathrm{ng} / \mu \mathrm{l}$ per reaction.

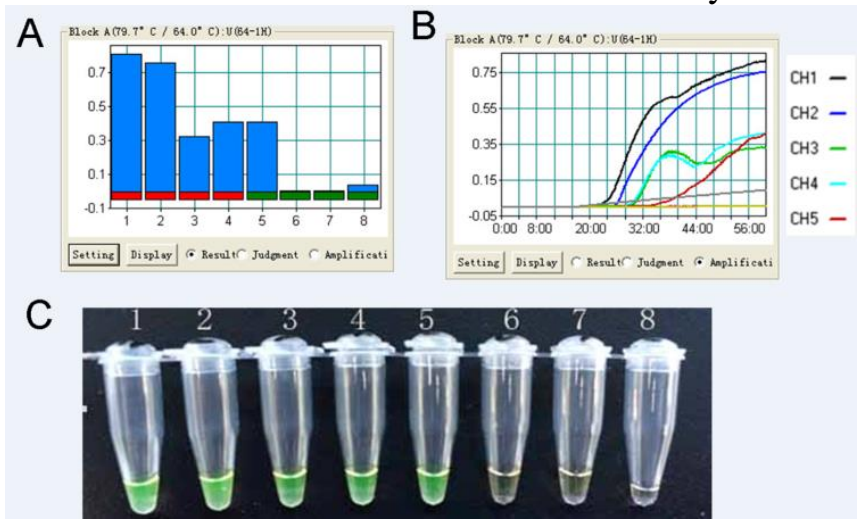

Figure 5. Sensitivity detection of LAMP methods for $P$. chinense. (A) The histogram of $P$. chinense primers sensitivity test amplification. (B) The graph of $P$. chinense primers sensitivity test amplification. CH1CH5 : Different concentrations of DNA with $10^{1}-10^{-5} \mathrm{ng} / \mu \mathrm{L}$. (C) Visual inspection of LAMP products by addition of fluorescent detection reagent. 1 - 7: Different concentrations of DNA with $10^{1}-10^{-5} \mathrm{ng} / \mu \mathrm{L}$. 8: Negative control

LAMP reaction can process in constant temperature within 90 minutes. LAMP detection procedure is simple, with fluorescent signals been observed without opening of the tubes. It has been shown that turbidity of LAMP reaction increases linearly with number of DNA template or longer incubation time ${ }^{[17]}$. Sixty minutes incubation was enough to allow minimal amount of template DNA to amplify a visible turbidity ${ }^{[17,18]}$. In this study, sensitivity which has been detected by naked eye and turbidity matched with each other (Fig 5). LAMP amplifies a very large amount of target DNA, which produces magnesium pyrophosphate as a by-product, visible as white turbidity ${ }^{[15-18]}$. In all cases, we could distinguish LAMP-positive samples from negative samples simply by color or turbidity of the reaction mixture. LAMP is attractive diagnostic method exploited in poor countries where facilities are rough. Furthermore, LAMP is rapid and does not require any specialized heating equipment.

\section{CONCLUSION}

In conclusion, the present study show a similarity in relative sensitivity of the TCM of LAMP method to real-time PCR assay. However, real-time PCR assay and LAMP reaction have shown superior sensitivity compared to conventional PCR used to detect $P$. chinense DNA. LAMP method and real-time PCR targeting ITS2 gene are rapid, sensitive, cost-effective and simple, which is a useful tool for molecular authenticity of traditional Chinese herbs ${ }^{[27]}$. Compared to PCR and other molecular biological techniques, LAMP and Real-time PCR which are commonly used in detecting traditional Chinese herbs are more practical under circumstances requiring a field diagnosis, such as entry and exit inspection and quarantine. This study reports the use of a LAMP technique for detection of traditional Chinese medicine for the first time, despite the stool samples in this study were artificially prepared. Further studies should be carried out to evaluate real value of this method, applying it to real life and settings in endemic situations. 


\section{REFERENCE}

1. Chan TYK. Incidence of Herb-Induced Aconitine Poisoning in Hong Kong. Drug Safety 2002; 25:823-828.

2. Lowe L, Matteucci MJ, Schneir AB. Herbal aconite tea and refractory ventricular tachycardia. N Engl J Med 2005; 353:1532.

3. Poon WT, Lai CK, Ching CK, Tse, KY., So, et al. Aconite poisoning in camouflage. Hong Kong Med J 2006; 12:456-9.

4. Fotiou F, Aravind S, Wang PP, Nerapusee O. Impact of illegal trade on the quality of epoetin alfa in Thailand. Clin Ther 2009; 31:336-46.

5. Gautam CS, Utreja A, Singal GL. Spurious and counterfeit drugs: a growing industry in the developing world. Postgrad Med J 2009; 85:251-6.

6. Marini RD, Rozet E, Montes ML, Rohrbasser C., Roht S., Rheme D., et al. Reliable lowcost capillary electrophoresis device for drug quality control and counterfeit medicines. J Pharm Biomed Anal 2010; 53:1278-87.

7. Busse W. The Significance of Quality for Efficacy and Safety of Herbal Medicinal Products. Therapeutic Innovation \& Regulatory Science 2000; 34:15-23.

8. Dondorp AM, Newton PN, Mayxay M, Van Damme, W., Smithuis, FM., Yeung, S., et al. Fake antimalarials in Southeast Asia are a major impediment to malaria control: multinational cross-sectional survey on the prevalence of fake antimalarials. Trop Med Int Health 2004; 9:1241-6.

9. Lee S, Lee T, Lee B, Choi H., Yang M., Ihm CG., et al. Fanconi's syndrome and subsequent progressive renal failure caused by a Chinese herb containing aristolochic acid. Nephrology (Carlton) 2004; 9:126-9.

10. Lo SH, Mo KL, Wong KS, Poon SP, Chan CK, Lai CK.,et al. Aristolochic acid nephropathy complicating a patient with focal segmental glomerulosclerosis. Nephrol Dial Transplant 2004; 19:1913-5.

11. Vanherweghem JL, Tielemans C, Abramowicz D, Depierreux M, Vanhaelen-Fastre R, Vanhaelen $\mathrm{M}$, et al. Rapidly progressive interstitial renal fibrosis in young women: association with slimming regimen including Chinese herbs. The Lancet 1993; 341:387-391.

12. Chen S, Yao H, Han J, Liu C, Song J, Shi L.,et al. Validation of the ITS2 region as a novel DNA barcode for identifying medicinal plant species. PLoS One 2010; 5:e8613.

13. Han J, Pang X, Liao B, Yao H, Song J, Chen S. An authenticity survey of herbal medicines from markets in China using DNA barcoding. Sci Rep 2016; 6:18723.

14. Zhou S, Hou Z, Li N, Qin Q. Development of a SYBR Green I real-time PCR for quantitative detection of Vibrio alginolyticus in seawater and seafood. J Appl Microbiol 2007; 103:1897-906.

15. Basuni M, Muhi J, Othman N, Verweij JJ, Ahmad M, Miswan N, et al. A pentaplex realtime polymerase chain reaction assay for detection of four species of soil-transmitted helminths. Am J Trop Med Hyg 2011; 84:338-43.

16. Notomi T. Loop-mediated isothermal amplification of DNA. Nucleic Acids Research 2000; 28:63e-63.

17. Mori Y, Notomi T. Loop-mediated isothermal amplification (LAMP): a rapid, accurate, and cost-effective diagnostic method for infectious diseases. J Infect Chemother 2009; 15:629.

18. Mori Y, Nagamine K, Tomita N, Notomi T. Detection of loop-mediated isothermal amplification reaction by turbidity derived from magnesium pyrophosphate formation. Biochem Biophys Res Commun 2001; 289:150-4.

19. Toma C, Lu Y, Higa N, Nakasone N, Chinen I, Baschkier A, et al. Multiplex PCR Assay for Identification of Human Diarrheagenic Escherichia coli. Journal of Clinical Microbiology 2003; 41:2669-2671.

20. Song T, Toma C, Nakasone N, Iwanaga M. Sensitive and rapid detection of Shigella and enteroinvasive Escherichia coli by a loop-mediated isothermal amplification method. FEMS Microbiol Lett 2005; 243:259-63.

21. Yasuhara-Bell J, Kubota R, Jenkins DM, Alvarez AM. Loop-mediated amplification of the Clavibacter michiganensis subsp. michiganensis micA gene is highly specific. Phytopathology 2013; 103:1220-6. 
22. Perandin F, Manca N, Calderaro A, Piccolo G., Galati L., Ricci L., et al. Development of a Real-Time PCR Assay for Detection of Plasmodium falciparum, Plasmodium vivax, and Plasmodium ovale for Routine Clinical Diagnosis. Journal of Clinical Microbiology 2004; 42:1214-1219.

23. Harper SJ, Ward LI, Clover GR. Development of LAMP and real-time PCR methods for the rapid detection of Xylella fastidiosa for quarantine and field applications. Phytopathology 2010; 100:1282-8.

24. Yang C, Jiang Y, Huang K, Zhu C, and Yin Y, et al. Application of real-time PCR for quantitative detection ofCampylobacter jejuniin poultry, milk and environmental water. FEMS Immunology \& Medical Microbiology 2003; 38:265-271.

25. Zhonggang Duan QH, Jinfen Yang. The optimum DNA extraction methods research in DNA barcoding indentification of traditional Chinese medicine. Traditional Chinese Drug Research \& Clinical 2009; 20:480-484.

26. Savan R, Igarashi A, Matsuoka S, Sakai M. Sensitive and Rapid Detection of Edwardsiellosis in Fish by a Loop-Mediated Isothermal Amplification Method. Applied and Environmental Microbiology 2004; 70:621-624.

27. Lin Z, Zhang Y, Zhang H, Zhou Y, Cao J, Zhou J. Comparison of loop-mediated isothermal amplification (LAMP) and real-time PCR method targeting a 529-bp repeat element for diagnosis of toxoplasmosis. Vet Parasitol 2012; 185:296-300. 